\title{
O IMPACTO DA PROTEÇÃO AOS ACIONISTAS MINORITÁRIOS: O CASO PETROBRÁS
}

\section{THE IMPACT OF PROTECTION FOR MINORITY SHAREHOLDERS: THE PETROBRAS CASE}

\begin{abstract}
GUILHERME AMORIM CAMPOS DA SILVA
Doutor em Direito Constitucional (2010) e Mestre em Direito do Estado (2002) pela PUC/SP. Professor do Programa de Mestrado em Direito da Uninove, orienta na linha de pesquisa Justiça e o Paradigma da Eficiência. Estuda o Direito Constitucional, a validade e a interpretação do direito, e as relações entre as empresas e o Poder Público na realização do desenvolvimento econômico nacional.
\end{abstract}

\section{RESUMO}

A governança corporativa pode ser considerada como fator de redução de risco aos investidores, no entanto, a proteção legal direcionada aos investidores minoritários não se configura de igual maneira no Brasil e nos Estados Unidos, o que acaba por refletir nas ações propostas nesses dois países com o objetivo de ressarcimento a esses investidores frente aos escândalos de corrupção envolvendo a Petrobrás.

PALAVRAS-CHAVE: Class Action; Governança Corporativa; Investidores Minoritários; Petrobrás.

\section{ABSTRACT}

Corporate governance can be considered as a risk reduction factor for investors, however, legal protection directed at minority shareholder is not the same in Brazil and 
the United States, which is reflected in the actions proposed in these two countries with the objective of reimbursing these investors against the corruption scandals involving Petrobras.

KEYWORDS: Class Action; Corporate Governance; Minority Shareholders; Petrobras.

\section{INTRODUÇÃO}

Nos mercados emergentes a governança corporativa pode ser considerada fator de redução do risco para os investidores, especialmente os minoritários, em virtude de uma proteção legal mais fraca nesses países. Nesse sentido poderia funcionar como uma proteção aos direitos dos acionistas minoritários frente aos administradores das companhias.

Não é segredo que bons índices de governança corporativa reduzem os riscos de investimentos, mas não se pode olvidar que outros riscos se encontram presentes, especialmente em países emergentes como o Brasil, em virtude das sucessivas crises econômicas, posto que a oportunidade de investimentos em uma companhia também depende de fatores macroeconômicos, bem como, da insegurança jurídica que impacta o custo Brasil, e, portanto, a disponibilidade para investir.

Assim é que esse estudo busca compreender a relação entre a proteção legal aos investidores na legislação brasileira e a adoção de melhores práticas de governança corporativa, tendo por base, as ações em face da Petrobrás em solo americano e em solo brasileiro.

A negociação das companhias brasileiras no mercado americano é possível com a utilização das ADRs, American Depositary Receipts, com a observância do disposto na Lei Sarbanes-Oxley de 2002, fruto de uma crise de credibilidade no mercado de ações americano e que impõe um conjunto de regras com vistas a certificar as informações emitidas pela companhia. As companhias brasileiras que negociam no mercado americano, o que aumenta a possibilidade de captação de recursos, estão sujeitas, além da observação do disposto na Lei Sarbanes-Oxley, a 
observação das regras de boa governança e ainda dos Securities Act de 1933 e de 1934, ambos fundamentos da class action proposta na Corte Federal de Nova lorque, nos Estados Unidos, em face da Petrobrás e outros, e que tem como origem os casos de corrupção na companhia e os possíveis prejuízos aos acionistas minoritários.

Uma ação similar foi proposta no Brasil pela Associação dos Investidores Minoritários (Aidmim), em dezembro de 2017, em São Paulo. A Ação Civil Pública em questão conta com pedido de extensão para o reconhecimento e condenação no dever de reparar os danos causados aos investidores brasileiros, baseando-se, no acordo celebrado em território americano, no valor de US\$2,95 bilhões.

Este trabalho está organizado em cinco seções. Além destas considerações iniciais, apresenta na seção dois a importância da adoção de medidas de governança corporativa e seus níveis. Na sequência, a seção três traz uma visão geral da proteção legal dos investidores no direito brasileiro e americano. A seção quatro analisa a Ação Civil Pública proposta pela associação que representa os acionistas minoritários e a class action proposta na Corte Federal de Nova lorque, nos Estados Unidos. A seção cinco apresenta as conclusões do estudo.

\section{A ADOÇÃO DE MELHORES PRÁTICAS DE GOVERNANÇA CORPORATIVA}

A governança corporativa figura entre os principais temas afetos a gestão empresarial e pode ser definida como uma forma de criação de um ambiente nas companhias, em que as pessoas procurem voluntariamente cumprir as regras e que tomem as melhores decisões no melhor interesse da organização (SILVEIRA, 2015, p.594-595). Em 1995 é fundado o Instituto Brasileiro de Governança Corporativa (IBGC), com o claro objetivo de melhorar a governança corporativa no país. Em 1999 é lançado, pelo Instituto, o primeiro código disciplinando o assunto, entre seus objetos o relacionamento entre os controladores e os minoritários, e ainda diretrizes para o 
conselho de administração ${ }^{1}$. Como princípios de governança apresenta a transparência, a prestação de contas, a equidade e a responsabilidade corporativa.

A governança corporativa, para Goyos Júnior (2003), deve ser compreendida como um esforço contínuo e organizado de acionistas e executivos dirigido à obtenção de melhor alinhamento entre os interesses da organização e dos stakeholders. A maneira que as companhias irão enfrentar os desafios e oportunidades depende das qualidades institucionais existentes, ou seja, depende da governança, que está estampada no conjunto de normas, crenças e procedimentos que regulam a coletividade. A governança, portanto, seria o primeiro determinante da governabilidade, somando-se à capacidade dos atores políticos, econômicos, sociais, do governo e à qualidade das lideranças que atuam na sociedade, Estado, mercado e organizações.

Afirma Alexandre Di Micele da Silveira (2015, P.594-690) a existência de ao menos dez princípios globais de governança corporativa, o princípio da transparência e integridade das informações, que está relacionado a divulgação aberta, honesta e tempestiva das informações financeiras e não financeiras, não apenas ao público interno, mas também ao externo. O princípio da prestação de contas voluntária e responsabilização pelas decisões tomadas, em que os administradores devem apresentar seus resultados e se responsabilizar pelas ações e omissões ocorridas durante sua gestão. O princípio da avaliação de desempenho e remuneração justa, o princípio dos contrapesos independentes no processo decisório, no sentido de que a implantação de um modelo de governança seja capaz de incentivar visões diferentes para a tomada da decisão. A sustentabilidade e a visão a longo prazo também constituem um princípio, e ainda o respeito as formalidades, controle e supervisão independentes, que se relacionam com a conscientização de que há necessidade de desenhar processos e estabelecer regras a serem cumpridas, entre esses controles incluídos nesse princípio destacamos o compliance e as auditorias.

O tom e o comportamento ético das lideranças, a cooperação entre colaboradores e a promoção do interesse coletivo, além da diversidade interna,

1 Vide Instituto Brasileiro de Governança Corporativa. 
tratamento justo aos stakeholders, e ausência de políticas discriminatórias completam os princípios da governança corporativa.

Um efetivo modelo de governança corporativa tende a melhorar as decisões empresariais das companhias, e, portanto, ao aumentar a probabilidade de cumprimento de regras, leva a melhores expectativas de geração de fluxo de caixa. Em virtude desse aprimoramento da gestão, aliada a um relacionamento mais estruturado entre os acionistas e os executivos, e, especialmente a redução da possibilidade de surpresas negativas, e maior transparência e credibilidade com os stakeholders, gera maior confiança e tendem a tornar as companhias mais atraentes aos investidores, beneficiadas, portanto, com um menor custo do capital próprio e de terceiros (SILVEIRA, 2015, p. 750-783).

A partir de 2002 com os escândalos no mercado de capitais americano, em que empresas como a Eron foram acusadas de fraudes contábeis, especialmente adulterações nos balanços contábeis, negociações de valores mobiliários com uso de informação privilegiada e evasão fiscal, o tema se tornou ainda mais corrente. Segundo Alexandre Di Miceli da Silveira (2015, p. 750-783) há diferenças inegáveis entre a questão da governança corporativa nas companhias americanas e nas companhias brasileiras. Nessas últimas a estrutura de propriedade é bem concentrada, diferente das primeiras que possuem estrutura de propriedades difusas, com muitos acionistas, em uma clara separação entre propriedade e controle. A situação das companhias brasileiras é de maior sobreposição entre propriedade e controle, em que se nota a presença marcante de um acionista controlador, que atua como gestor da companhia ou indica alguém de sua confiança para o cargo, em que no caso específico da Petrobrás a União Federal é a controladora, com participação ainda do Banco Nacional de Desenvolvimento Econômico e Social Participações S/A (BNDESPAR).

Essa é a razão para que a governança corporativa nas companhias americanas tenha traços distintos da observada nas companhias brasileiras. Dificilmente haverá em companhias americanas acionistas com mais de $20 \%$ das suas ações, assim, acionistas fracos frente a executivos com maior relevância, acarretam a necessidade de um alinhamento de interesses dos executivos e dos acionistas e o 
uso de mecanismos internos, como um conselho de administração ativo e independente, ou mesmo por mecanismos externos, como um mercado de aquisição hostis ativo. Já nas companhias brasileiras, ante a concentração de propriedade, os principais embates ocorrem entre os controladores e os acionistas minoritários e os credores de longo prazo. Esse é o motivo pelo qual a proteção aos acionistas minoritários é importante, assim como, a transparência das decisões tomadas pelos controladores e a garantia de alguma voz aos acionistas minoritários, como a participação no conselho de administração.

Se as companhias brasileiras possuem estrutura muito concentrada de propriedade, como assegura os estudos de Leal et al. (2002), com alto índice de emissão de ações sem direito a voto, se há alguma pulverização dessa propriedade ela ocorre por meio dessas ações, o que acaba por permitir aos majoritários manter o controle mesmo que sua participação no capital da empresa seja menor. A necessidade de acesso ao mercado de capitais vem, de alguma forma, impulsionando o aprimoramento das práticas de governança corporativa nas companhias brasileiras. A aprovação da nova Lei das Sociedades Anônimas, Lei n.ำ 10.303/2001, e a revisitação do Códigos de Governança Corporativa do IBGC e ainda a criação do Código de Governança Corporativa da Comissão de Valores Mobiliários (CVM), bem como a criação de níveis diferenciados de governança corporativa na BOVESPA, perfazem uma tentativa institucional e governamental de adequação.

Uma das funções das práticas de governança corporativa é proteger os acionistas de expropriações indevidas por parte dos administradores e controladores das companhias (CHEN, CHEN, WEI, p.3). Na definição de La Porta et al. (2000, p. 3-27) constituem uma série de mecanismos pelos quais um investidor externo pode se proteger de expropriações realizadas pelos membros da companhia. Ainda que as oportunidades de investimentos estejam atreladas a condições macroeconômicas há uma relação entre a expropriação realizada e a temperatura do mercado. De maneira que há maior risco de expropriações quando o mercado se encontra em queda do que quando o mercado está em ascendência (DURNEC, KIM, 2005, p. 1461-1493). Ao passo que melhores práticas de governança corporativa reduzem os custos de monitoramento dessas companhias. Em geral os investidores ao analisar o grau de 
retorno de seus investimentos levam em consideração essas práticas, porque acabam por exigir um retorno maior das companhias com menor nível de governança corporativa, ante os custos de monitoramento, que nessas companhias são mais altos.

O uso de informações privilegiadas também é combatido pelas práticas de governança corporativa, de forma que, aparentemente, seria possível afirmar que melhores práticas de governança corporativa teriam como efeito a redução do custo do capital.

A maior parte dos estudos sobre governança corporativa o realiza baseado em três premissas. A primeira é a de que mecanismos de governança são variáveis exógenas, a segunda, a causalidade, apresenta um sentido único da governança corporativa para o desempenho, e por fim, a de que as regressões são rodadas por meio de equações isoladas, usando um ou mais dos mecanismos de governança. Os mecanismos de governança mais comumente empregados são os mecanismos internos, tais como, concentração de poder, a estrutura das comissões e a remuneração dos executivos, e mecanismos externos, como, competição e controle do mercado, a alavancagem financeira, e a proteção ao investidor.

No Brasil, Leal e Carvalhal da Silva, no estudo da relação entre o valor da companhia e as práticas de governança corporativa realizado entre 1998 e 2002, demonstraram de fato uma relação entre a melhora nas práticas de governança corporativa e o aumento no valor das ações no mercado. É notório que a pouca proteção aos investidores causa embaraços para o financiamento das empresas brasileiras, e ante a dificuldade na mudança da legislação para a proteção mais eficiente dos pequenos investidores a BOVESPA criou o chamado Novo Mercado.

O Novo Mercado, inspirado no Neuer Markt Alemão, lista papéis apenas das companhias que aderem a melhor proteção dos acionistas minoritários e que passam a tratar suas contas com maior transparência. Sem dúvida a meta desse projeto seria desenvolver o mercado de capitais no Brasil, dando, maior destaque aos esforços das companhias na melhoria de sua relação com os investidores (SPROUR, p. 9-10). Essa ideia não é inovadora, a convergência funcional é a possibilidade de "promover mudanças nos contratos privados sem necessidade de uma alteração mais ampla na 
legislação" (SPROUR, p. 9), Coffee idealizou tal processo pela possibilidade de companhias com sede em países de fraco aparato societário se listarem em bolsas de países com regras mais rígidas de governança (COFFEE apud SPROUR, p. 9-10).

Mas há estudos, dentre eles o de Grossman e Hart (1986, p. 691-719), que apontam que essa convergência funcional não é capaz de suplantar a falha na legislação de proteção aos acionistas minoritários, e que, no caso de falha ou lacuna da legislação o contrato privado acabaria por ter sua eficácia reduzida. Para Johnson e Shleifer (2001) a proteção dos investidores minoritários deve estar associada a instituições de sólidas regras internas de regulação e de transparência, o que permitiria, inclusive ao judiciário, uma melhor base decisória.

A possibilidade descrita por Coffee é a realizada na bolsa americana. Empresas estrangeiras que desejem listar suas ações nesse mercado o fazem através das ADRs, American Depositary Receipts, que contam com quatro tipos, de acordo com níveis de transparência, regras de contabilidade, práticas de governança e mecanismos de colocação desses papéis, que podem ser realizados no mercado de balcão ou na própria bolsa em questão. As firmas estrangeiras listadas na bolsa americana, dentre elas a Petrobrás, precisam observar algumas normas relativas à proteção dos acionistas minoritários e que são úteis na melhoria da governança corporativa, são elas: a seção 13(d) da SEC Act que determina que qualquer grupo que detenha mais de $5 \%$ do capital da companhia lhe informe imediatamente, a seção 14(d) da SEC Act que determina que, em qualquer oferta de fechamento de capital, deve-se garantir o mesmo preço aos acionistas minoritários, inclusive aqueles que tem ações no mercado de origem da companhia, e ainda a Seção 13(e) da SEC Act que permite a agência regular o tratamento dado aos acionistas minoritários diante de negócios privados do controlador, a regra 10b-5 que dá ao acionista minoritário o direito de reembolso em transações fraudulentas realizadas pelo controlador, bem como pelo Foreign Corrupt Practices Act a companhia deve manter todos os livros de contabilidade e registros de maneira transparente para evitar corrupção e por fim como estão sujeitas as regras das bolsas americanas em alguns casos é possível requerer, a exemplo da NYSE, que a companhia tenha ao menos dois conselheiros 
externos no conselho de administração, além de auditores independentes e de exigências de quórum qualificado em assembleias.

No caso específico da Petrobrás é notório que o esquema de corrupção revelado pela operação Lava Jato que envolvia a companhia e alguns de seus diretores teve reflexos em sua credibilidade perante não apenas o mercado nacional como o internacional, em virtude da negociação de ações no mercado Americano. Além da queda no preço do petróleo, o escândalo mencionado, prejudicou sua situação econômica, e como resposta em 2014, a companhia anunciou a criação de uma nova diretoria de governança corporativa e compliance. Ainda assim chegou a ser suspensa do quadro de associados no IBGP, sob o fundamento de que não bastava à companhia a descrição de práticas de governança robustas, mas sim era necessária à sua realização. Uma das falhas apontadas na estrutura da governança corporativa da Petrobrás reside na pouca independência do conselho administrativo e nas estruturas inadequadas de monitoramento da diretoria. Há um dissenso entre o conselho de administração e seus stakeholders.

Já no ano vigente a Petrobrás migrou para o segmento Nível 2 de governança corporativa na Bolsa de Valores B3. Tal nível se configura em um patamar intermediário entre o Nível 1 e o Nível Novo Mercado da BOVESPA. Para tanto a companha ampliou as atribuições do Comitê dos Minoritários, que, a partir de maio de 2018, passou a fazer o assessoramento prévio aos acionistas em situações críticas, como a aprovação de fusões com outras empresas, e contratos entre o governo e a companhia. Acrescente-se a essas medidas novas regras para a oferta pública de ações e a previsão de procedimento arbitral para solucionar questões. Todas essas medidas visam, sem dúvida, inspirar maior confiança nos investidores, bem como, maior transparência e um tratamento mais equânime a todos os acionistas. 


\section{UMA VISÃO GERAL DA PROTEÇÃO LEGAL AOS ACIONISTAS MINORITÁRIO NO DIREITO BRASILEIRO E NO DIREITO AMERICANO}

Sem dúvida o interesse no acompanhamento das companhias abertas se deve à proteção do investidor, especialmente, os minoritários. A Lei 7913/1989, criada antes mesmo do maior desenvolvimento do mercado mobiliário no Brasil e que disciplina especificamente o mercado de capitais, prevê a legitimidade ativa ao Ministério Público para propor, seja de ofício ou a requerimento da CVM, ação civil pública com o objetivo de proteger de maneira coletiva os investidores contra condutas ilícitas, como fraudes, inside tradings, ou mesmo a violação ao dever de disclosure, visando, portanto, evitar prejuízos ou mesmo buscando o ressarcimento de eventuais danos causados aos titulares de valores mobiliários e ainda dos investidores. Tal solução legislativa não é impassível de críticas ante a possível existência de confusão entre os direitos individuais passíveis de proteção coletiva e aqueles de fato difusos.

Conforme demonstra Fernando Antônio de Alencar Alves de Oliveira Júnior (2017, p. 224-261), passadas quase três décadas da vigência da Lei em comento não houve por parte da jurisprudência uma contribuição substancial para a aplicação de seus dispositivos, contando o Superior Tribunal de Justiça com 10 acórdãos, no período entre 1992 a 2004², com referência à Lei 7913/1989, sem que nenhum desses acórdãos tenha origem específica em alguma ação civil pública movida pelo Ministério Público para prevenir ou reparar quaisquer danos oriundos do mercado de capitais.

Se o direito é indispensável tanto à configuração quanto ao funcionamento dos mercados financeiros, o sistema financeiro não existe fora de um sistema normativo. Conforme afirma Katharina Pistor os mercados financeiros são construídos de maneira essencialmente híbrida, algo entre o mercado e o estado, entre o público e o privado PISTOR, 2013, p.3-6). Ativos financeiros são contratos, e seu valor

\footnotetext{
${ }^{2} \mathrm{~A}$ ação civil pública movida em face a Petrobrás em virtude dos prejuízos causados aos investidores minoritários, não foi proposta pelo Ministério Público, e, sim, pela Associação que os representa, conforme veremos em momento posterior. Quanto ao número de acórdãos com referência específica à Lei 7913/1989 vide Superior Tribunal de Justiça. Disponível em: $<$ http://www.sti.jus.br/SCON/jurisprudencia/toc.jsp?livre=Lei+7913\&\&tipo visualizacao=RESUMO\&b= ACOR>.
} 
depende da possibilidade legal de sua execução. Se esses ativos financeiros serão ou não justificáveis, e, portanto, passíveis de execução, é uma função das normas e da interpretação realizada pelos tribunais ou pelos órgãos de controle, o que certamente irá depender e variar em cada sistema normativo (PISTOR, 2013, p. 3-6).

Assim é que não se pode ignorar o público alvo do investimento, nem mesmo as incertezas presentes nas atividades financeiras. Em um mundo em que o capital circula livremente, as normas que regem os mercados financeiros e que conectam os diferentes investidores, de diferentes países, e, portanto, de diferentes sistemas normativos, determinam o fim do sistema financeiro (PISTOR, 2013, p. 3-8). Nesse mercado, a habilidade de criação de instrumentos, que não conflitem com as regras existentes nos mais diversos sistemas normativos e jurisdições, mesmo as que tem como objetivo mitigar eventuais prejuízos causados aos investidores, constitui uma vantagem. Como afirma Katharina Pistor (2013, p. 3-8), há, em verdade, um processo dinâmico em que as regras do jogo são continuamente desafiadas por novos contratos.

Afirma ainda Katharina Pistor (2013, p. 3-8), que a não observância de algumas normas é o que poderia garantir a sobrevivência do mercado financeiro. No entanto, não se trata aqui da prática de atos ilícitos, previstos na Lei 7913/1989, e que legitimam a propositura de ação civil pública para reparação de danos causados aos investidores, mas, há que se reconhecer que em situações de crise os investidores menores têm menor capacidade de escapar dos efeitos deletérios, como se nota no caso Petrobrás, por isso, reconhece a autora que o direito é mais elástico no topo da hierarquia e mais rígido na base.

Essa é razão para que os instrumentos coletivos sejam um meio adequado para a proteção dos acionistas não controladores no mercado de capitais. Ainda que diferenças existam entre as class actions e a ação prevista na Lei 7913/1989. O processo coletivo, na definição de Fred Didier e Hermes Zaneti (2016, p. 30) é aquele em que se postula um direito coletivo lato sensu, ou seja, uma situação jurídica coletiva ativa, ou aquele em que se afirme a existência de uma situação jurídica coletiva passiva de titularidade de grupo de pessoas, como os deveres individuais homogêneos. 
Para Arruda Alvim (2005, p. 77), a ação civil pública nasceu para proteger novos bens jurídicos, e se refere a uma nova pauta de bens ou valores, "marcados pelas características do que veio a ser denominado de interesses e direitos difusos ou coletivos", profundamente "diferentes ou 'opostas' às da categoria clássica dos direitos subjetivos, que marcaram o direito privado e o processo civil tradicional".

Cabe ao Ministério Público a defesa de interesses sociais, em virtude de mandamento constitucional, conforme prevê o artigo 127, caput, da Constituição Federal, bem como, para promover, por meio do inquérito civil público e da ação civil pública, a proteção de interesses difusos e coletivos (art. 129, inciso III), a Lei de Ação Civil Pública, em seu artigo $5^{\circ}$, $\S 1^{\circ}$, o Código de Defesa do Consumidor - CDC, art. 82, inciso I, e art. 92 e o novo Código de Processo Civil - NCPC, art. 178, inciso I, que preveem a atuação do Ministério Público, se não como parte, como custos iuris, desses feitos.

Um dos equívocos apontados na Lei 7913/1989, é que ao analisar seus dispositivos, percebe-se a menção apenas a direitos individuais homogêneos a serem tutelados. De forma que há discrepância entre o direito que se pretende proteger e o de fato protegido. Sem dúvida o investidor do mercado de capitais ao buscar o ressarcimento decorrente de prática de ato ilícito, o faz com fundamento em um direito de natureza individual homogênea, posto que é possível, ao menos em tese, calcular o prejuízo sofrido por cada sujeito, identificando os titulares dos valores mobiliários. Mas na seara da proteção preventiva, não sendo esse o caso Petrobrás sob análise, o direito protegido pode ser difuso, porque pode ser considerado de maneira abstrata, para aqueles que venham a investir no mercado de capitais, ou ainda, coletivo, quando em relação a determinado grupo de detentores de valores mobiliários.

A Lei 7913/1989 é de iniciativa da CVM, com inspiração na legislação americana, que prevê na seção 20(b) do Securities Act a legitimação da Securities and Exchange Comission (SEC) para tomada de medidas judiciais com o fim de impedir a prática de determinados atos lesivos aos investidores, bem como, com o de reparar os prejuízos causados aos investidores, obrigando aos que praticaram o ato ilícito a depositarem os lucros assim obtidos. Pela legislação americana, é ainda possível, à SEC, solicitar ao poder judiciário a remoção dos administradores das 
companhias que estejam lesando os interesses dos acionistas minoritários. Sem dúvidas um papel mais amplo que aquele previsto na Lei 7913/1989 à CVM, quando da alteração do projeto, por proposta da Procuradoria Geral da Fazenda Nacional, para conferir apenas ao Ministério Público a iniciativa da ação civil pública no interesse dos investidores do mercado mobiliário. $O$ objetivo da lei seria o de proteção ao consumidor, que é o investidor no mercado de valores mobiliários, e, que, em geral é despreparado para enfrentar os mecanismos sofisticados de negociação na Bolsa de Valores e no mercado de balcão (EIZIRIK, 1992, p. 157-158).

Interessante notar que o julgamento das ações civis públicas não é feito por juízo especializado, o que não ocorre nos julgamentos das class actions nos EUA, posto que as ações que questionam fatos ocorridos no mercado de capitais americano são mais comuns do que no Brasil. Não se trata, sob a égide da Lei 7913/1989, da propositura de ações civis públicas para quaisquer prejuízos decorrentes da atividade no mercado de capitais. Como dito anteriormente, o mercado de valores mobiliários é um mercado de risco, ademais, existem outras ações que inferem a responsabilidade por danos acusados por administradores, na legislação societária, como é o caso do artigo 159 da Lei das SAs.

A Lei 7913/1989 tem como objetivo maior a proteção dos acionistas minoritários, ou seja, dos acionistas não-controladores, expressão essa utilizada pelo professor Fábio Konder Comparato (2008, p. 310), para quem a expressão 'acionista minoritário' não é unívoca na lei.

As ações sem direito a voto dominam o mercado de capitais no Brasil, que apresenta uma alta concentração da estrutura de controle das empresas, como visto anteriormente. Em pesquisa realizada em 225 empresas listadas na BOVESPA, Ricardo Pereira Câmara Leal, André Luiz Carvalhal da Silva e Silvia Mourthé Valadares, identificaram que 155 , ou seja, $69 \%$, tinham um único acionista que possuía mais de $50 \%$ do capital votante. Ainda que ausente um acionista majoritário, o maior acionista, possuía uma parcela significativa do capital votante (LEAL, SILVA, VALADARES, 2002).

Para os ilícitos descritos na Lei 7913/1989, especialmente aqueles previstos nos incisos do artigo 1ํ, o dever de informar, qual seja, o direito à informação verídica, 
é fundamental. Dele decorre a proteção contra operações fraudulentas, manipulações de preço, criações artificiais de procura, oferta ou preço de valores mobiliários. Mas não é na Lei 7913/1989 que esse dever de informar se encontra, e sim, na Lei das SAs, que em seus artigos 115,116, parágrafo único e 117, prevê deveres como o de diligência, o de buscar o interesse social com lealdade, e o dever de informar.

Em um mercado mais ativo e competitivo, e, ainda com um alto grau de alavancagem a importância da transparência nas práticas empresariais se acentua. Nesse sentido a governança corporativa surge como um mecanismo desse processo. A transparência das informações, minimizando a diferença de acesso à informação entre controladores e acionistas minoritários, diminuindo o custo de captação das companhias, torna possível aos investidores uma tomada de decisão mais respaldada. A Lei 10303/2001 buscou propiciar aos acionistas minoritários uma redução nos riscos e uma maximização de sua participação no controle da companhia ${ }^{3}$.

Essa tentativa decorre da estrutura do mercado brasileiro, que como visto, tem alto índice de concentração acionário, buscando torna-lo mais atraente e acessível ao pequeno investidor. Práticas de governança que visem proporcionar um tratamento mais igualitário entre os acionistas são consideradas fundamentais, como aquelas adotadas recentemente pela Petrobrás. No entanto, as mudanças

\footnotetext{
3 Uma das principais mudanças introduzidas por esta lei são a instituição da volta do direito de tag along e as alterações nas regras de fechamento de capital. São importantes alterações no que concerne ao alinhamento de interesses entre os acionistas, controladores minoritários e ao modelo de gestão transparente. O direito de tag along consiste em uma garantia dos acionistas que não possuem ingerência sobre o controle da companhia e: assegura que a alienação, direta ou indireta, do controle acionário de uma companhia somente poderá ocorrer sob a condição de que o acionista adquirente se obrigue a fazer oferta pública de aquisição das demais ações ordinárias, de modo a assegurar a seus detentores o preço mínimo de $80 \%$ do valor pago pelas ações integrantes do bloco de controle. Vide: BOVESPA. Disponível em : <www.bovespa.com.br>. Acesso em: 28 set. 2018. E ainda, de acordo com as novas regras para fechamento de capital, uma companhia só pode fechar seu capital se oferecer aos demais acionistas um preço justo por suas ações. Aqui caberá à CVM, no papel de reguladora do mercado de valores mobiliários, estipular um critério para a aferição deste preço. É possível identificar outra inovação que se consubstancia na limitação da possibilidade de resgate de ações pela companhia somente no caso de restarem $5 \%$ ou menos das ações no mercado após uma oferta pública para fechamento. O IBGC aponta ainda inovações como as que incluem algumas modificações nas vantagens atribuídas às ações preferenciais, tornando-as mais atrativas para o investidor, a explicitação de regras para membros do conselho fiscal e a possibilidade de inclusão de cláusulas de arbitragem nos estatutos sociais das companhias. Vide: IBGC. Disponível em: <www.ibgc.com.br>. Acesso em: 28 set. 2018.
} 
observadas na LSAs são modestas, como afirma Koslowiski (2004, p. 32), a opção feita pelo legislador, acabou por incentivar o afastamento dos minoritários, de maneira que a ideia de fortalecimento do mercado "encontra uma barreira quase que intransponível que parte da própria LSA".

O papel da CVM, que tem como função a promoção do mercado de valores mobiliários, e que edita em 2002 uma cartilha sobre práticas de boa governança corporativa, é, nesse caso específico, meramente recomendatório. Caberia, portanto, um fortalecimento das esferas administrativas, dentre elas a CVM, que, como afirma Koslowiski "refoge à intervenção clássica, nas modalidades supletivas e substitutivas, e se aproxima da presença incentivadora com a instituição de sanções premiais" (KOLOWISKI, 2004, p. 33).

Em 2002, nos EUA, a Lei Sarbanes-Oxley ${ }^{4}$, considerada a maior reforma do mercado de capitais desde a quebra da bolsa de Nova lorque em 1929, promoveu uma ampla regulamentação da vida corporativa, como assinalam Adriana Andrade e José Paschoal Rossetti (2004, p. 85). Consolida práticas de boa governança corporativa, dando especial destaque à prestação responsável de contas e a transparência. Aliada a essas práticas disciplina uma série de determinações com o objetivo de aumentar o grau de responsabilidade de diversos stakeholders, desde o presidente da companhia, passando pelos funcionários e os advogados por ela contratados.

Seu foco se encontra em quatro valores primordiais, o compliance, compreendido como a conformidade legal, o accountability, que é a prestação responsável de contas, o disclosure, que é maior transparência, e, por último, o fairness, que é o senso de justiça. Dentre esses valores se destacam as diretrizes de adoção de um código de ética, especialmente destinado aos principais executivos, com cópia para a SEC, a revisão dos relatórios, a não existência de falsas declarações, ou omissões de fatos relevantes, bem como demonstrações financeiras que espelhem a real situação da companhia, as informações relativas à situação financeira, ou qualquer outra informação complementar aos relatórios exigidos pela

${ }^{4}$ Assim denominada em homenagem aos congressistas Paul S. Sarbanes e Michael Oxley. 
lei, devem ser divulgadas com a maior rapidez possível, e a previsão de penas para as fraudes, em multas que podem alcançar US $\$ 5$ milhões e a prisão por um período de 20 anos.

A Lei Sarbanes-Oxley possui medidas tendentes à fiscalização das atividades de auditoria e normas que visam à repressão de fraudes praticadas pelos administradores das companhias. A Public Company Accounting Oversight Board (AOB), funciona como uma espécie de comissão de fiscalização das companhias abertas, composta de maneira paritária entre advogados, executivos das companhias e membros da SEC. Ao passo que os executivos passaram a ter de revisar de maneira detalhada os balanços e relatórios publicados e entregues à SEC. E ainda tem a obrigatoriedade de informar qualquer desvio nas informações ali contidas, com intuito de conferir maior transparência às demonstrações financeiras, prevendo até mesmo, a devolução de bônus e lucros distribuídos, no caso de nova publicação das demonstrações por não cumprimento das exigências formais, que resultem em alteração dos resultados da companhia, com a previsão de multas e de pena de prisão.

As companhias brasileiras que negociam papéis na bolsa de Nova lorque devem adimplir as obrigações constantes na Sarbanes-Oxley, o que poderia gerar alguns conflitos em virtude de diferenças nos sistemas normativos. Mas como afirma Milton de Nassau Ribeiro: "as companhias brasileiras que emitem valores mobiliários no mercado norte-americano poderão optar por instalar um comitê de auditoria nos moldes da SOX ou por adaptar os conselhos fiscais já existentes" (RIBEIRO, 2007, p. $34)$.

A Petrobrás, que no ano de 2010, efetuou a maior capitalização em capital aberto, no valor de US\$72,8 bilhões, obteve, em 2014, um prejuízo de $R \$ 21,587$ bilhões. Com a revelação pela operação Lava Jato de um esquema de corrupção e de suposta lavagem de dinheiro envolvendo a companhia, cujo acionista majoritário é a União, e com a revelação dos depoimentos do ex-diretor de abastecimento, Paulo Roberto Costa, que davam conta de um sobre preço de $3 \%$ em todos os projetos liberados pela área de abastecimentos para pagamento de propinas por um cartel de empresas a alguns funcionários da companhia, seu valor de mercado é abruptamente 
reduzido 5 .

Nesse momento, a relação entre os acionistas minoritários e a companhia entra em crise. Há uma queda aguda no valor das ações, com causa relacionada com fraudes solucionadas pela Lava-Jato, o que tem como consequência a perda de valor considerável na negociação dos papéis da companhia. É preciso destacar que a simples desvalorização de ações no mercado americano não é fundamento para a propositura das class actions, da mesma forma, que não se configuram em fundamento para a propositura da ação civil pública prevista na Lei 7913/2001. Mas uma vez comprovada a má prática, por violação aos valores previstos na Lei SarbaneOxley, em que se vislumbre o nexo de causalidade entre a conduta e o prejuízo ao investidor, haverá fundamentos para a propositura de tal ação, como se vislumbra na class action proposta em território americano.

\section{O CASO PETROBRÁS}

Proposta em outubro de 2017, movida pela Aidmim, a Ação Civil Pública ${ }^{6}$ em face da Petrobrás, objetiva o ressarcimento dos prejuízos sofridos pelos investidores que adquiriam ações da companhia na BM\&FBovespa, em razão de informações falaciosas prestadas aos mercado, e, em virtude de esquema de corrupção, alavancagens mentirosas ao mercado, além de projetos que jamais se realizariam e/ou eram sabidamente inviáveis, deflagrados pela Operação Lava a Jato. As alegações trazidas pela Associação autora dão conta de que o esquema de corrupção perdurou por aproximadamente nove anos.

Os investidores da Petrobrás poderiam ser divididos em investidores nacionais que adquiriam as ações negociadas na BM\&FBovespa - PETR3 (ON) e PETR4 (PN), e investidores internacionais, que investiram em ações com a aquisição

\footnotetext{
${ }^{5} \mathrm{~A}$ agência Moody's, em outubro, já havia voltado a rebaixar o rating da dívida em moeda estrangeira da Petrobras, de Baa1 para Baa2,e, posteriormente rebaixado para Baa3. As razões foram as mesmas do rebaixamento anterior: a alta alavancagem financeira e a possibilidade de postergação para depois de 2016 do declínio da mesma, contrariamente às expectativas originais da agência.

${ }_{6}^{6}$ Ação Judicial no 1106499-89.2017.8.26.0100 em curso junto ao Tribunal de Justiça de São Paulo.
} 
de ADRs negociadas na Bolsa de Nova lorque. Alegam ainda que o valor patrimonial da Petrobrás reduziu, naquele período, o equivalente a $43,6 \%$ do seu valor de mercado. Sendo esses prejuízos severos, fruto de má gestão consciente. Informam ainda que houve por parte da companhia na alavancagem e comercialização de ações a utilização de informações falsas.

Para além das questões referentes à legitimidade e competência para a apreciação da demanda em si, a Autora afirma haver responsabilidade por ato ilícito por parte da Petrobrás, em conformidade com o disposto no artigo $1^{\circ}$ da Lei Federal n. $.7913 / 89$, que disciplina a Ação Civil Pública de responsabilidade por danos causados aos investidores no mercado de valores mobiliários, especialmente as decorrentes de operação fraudulenta, omissão de informação relevante por parte de quem estava obrigado a divulga-la, bem como sua prestação de forma incompleta, falsa ou tendenciosa. Alegam ainda o descumprimento da Lei Federal n.. 6404/76, no tocante aos deveres dos administradores, tais como os deveres de obediência e diligência, descritos no artigo 153 do referido diploma legal, e ainda, o dever de lealdade, descrito no artigo 155, e o dever de informar, previsto no artigo 157 , parágrafo $4^{\circ}$ e 176.

Sem ignorar a não observância dos princípios básicos de governança corporativa e ainda a infração dos deveres prescritos em lei, ou nos estatutos, e que respondem em conformidade com o disposto no artigo 158, incisos I e II da Lei Federal n. ${ }^{\circ}$ 6404/76 e artigos 186 e 927 do Código Civil Brasileiro. Insta ressaltar a Instrução n. -358 de 2002 da CVM que determina que a divulgação de ato ou fato relevante deve ser realizada de maneira clara e precisa, em linguagem acessível ao público investidor.

Esse é o panorama da ação proposta em território nacional para o ressarcimento dos prejuízos dos investidores minoritários. Panorama e resultado diversos são aqueles existentes na class action proposta na Corte Federal de Nova Iorque. Inicialmente cumpre destacar que em contraposição à ação proposta no Brasil 
a class action tem como réus não apenas a Petrobrás como também auditores, instituições financeiras, diretores, empresas afiliadas, dentre outros ${ }^{7}$.

As alegações possuem de fato o mesmo pano de fundo, o escândalo de corrupção exposto com as investigações deflagradas com a Lava a Jato, que supostamente se iniciam na primeira década desse milênio, momento em que a Petrobrás expande sua capacidade de produção. Os processos de licitação fraudados, com preços superfaturados alimentavam uma extensa rede de corrupção. A partir do momento em que os detalhes desse escândalo passaram a ser revelados o valor da companhia no mercado caiu de maneira abrupta.

Outras class action foram propostas, bem como ações individuais com os mesmos argumentos. As alegações dão conta de que no período entre 22 de janeiro de 2010 e 28 de julho de 2015 os réus realizaram dois tipos de declarações falsas em direta violação à Seção 10(b) do Exchange Act e Rule 10b-5. Em primeiro lugar a Petrobrás produziu demonstrações financeiras com aumento de ativo, segundo, garantiram aos investidores que a companhia aderiu a uma série de princípios éticos e que mantinha um controle severo nas contas a fim de prevenir a fraude e a corrupção. Acrescente-se a essas alegações a afirmação de que a Petrobrás e as instituições financeiras intermediárias na venda de valores mobiliários - Underwriter, prestaram informações materialmente falsas nas declarações registradas e outros documentos conexos, o que feria o previsto na Seção 11, 12(a)(2) e 15 do Securities Act.

\footnotetext{
7 Petróleo Brasileiro S.A. - Petrobras ("Petrobras"), Petrobras Global Finance B.V. ("PGF") e Petrobras America Inc. ("PAI"); BB Securities Ltd., Citigroup Global Markets Inc., J.P. Morgan Securities LLC, Itaú BBA USA Securities, Inc., Morgan Stanley \& Co. LLC, HSBC Securities (USA) Inc., Mitsubishi UFJ Securities (USA), Inc. (n/k/a MUFG Securities Americas Inc.), Merrill Lynch, Pierce, Fenner \& Smith Incorporated, Standard Chartered Bank, Bank of China (Hong Kong) Limited, Banco Bradesco BBI S.A., Banca IMI S.p.A. e Scotia Capital (USA) Inc.; Pricewaterhouse Coopers Auditores Independentes ("PwC Brazil"); Almir Guilherme Barbassa, Jose Carlos Cosenza, Paulo Roberto Costa, Renato de Souza Duque, Guillherme de Oliveira Estrella, Maria das Graças Silva Foster, Jose Miranda Formigli Filho, José Sergio Gabrielli, Silvio Sinedino Pinheiro, Daniel Lima de Oliveira, José Raimundo Brandão Pereira, Sérvio Túlio da Rosa Tinoco, Paulo Jose Alves, Gustavo Tardin Barbosa, Alexandre Quintão Fernandes, Marcos Antonio Zacarias, Cornelis Franciscus Jozef Looman, Theodore M. Helms esses como réus individuais, Banco Votorantim Nassau Branch, Santander Investment Securities Inc., Petrobras International Finance Company. Disponível em: <http://www.petrobrassecuritieslitigation.com/docs/LFN.pdf>. Acesso em: 15 set. 2018.
} 
No Brasil a ação civil pública em questão foi julgada extinta em 04 de julho de 2018, pela Juíza Lúcia Caninéo Campanhã, da 6ª Vara Cível de São Paulo, sob o argumento de que o estatuto da Petrobrás determina que todos os acionistas se submetam à arbitragem, "posto que submetem-se à vontade da maioria, às deliberações das assembleias e aos estatutos sociais, desde sempre". Afirmando ainda, que caberia aos acionistas discordantes a venda de suas ações, no ano de 2002, ou seja, anteriormente ao período de desvalorização. De forma que a Associação não poderia blindar ou eximir os acionistas de se submeterem à arbitragem ${ }^{8}$.

Outro desfecho é o da class action junto à Corte Federal de Nova Iorque. Ainda que não tenha reconhecido culpa ou prática de atos irregulares, conforme nota da própria companhia (PETROBRÁS, 2018), o acordo, cujo objetivo é encerrar as demandas em curso ou outras que possam ser propostas por investidores em ações e bônus adquiridos nos EUA, foi fechado no valor de US $\$ 2,95$ bilhões. O risco de um julgamento por um júri popular e as diferenças da legislação processual e do mercado de capitais foram os fatores alegados pela companhia para justificar referido acordo.

E ainda, em setembro de 2018, a companhia informou que fechou acordos com o Departamento de Justiça (DOJ) e a SEC para encerrar as investigações sobre as falhas nos controles internos, evidenciado pelos esquemas revelados na Lava Jato, e ainda as falhas nos registros contábeis e nas demonstrações financeiras, em que cada um receberá o equivalente a US $\$ 85,3$ milhões $(G 1,2018)$. O acordo junto à SEC visa especificamente encerrar as alegações de que ex-executivos da companhia cometeram violações ao Securities Act 1933 e ainda das previsões sobre registros contábeis, controles internos e arquivamento de informações falsas previstos no Securities Exchange Act of 1934.

No Brasil até o momento a Petrobrás firmou acordo com o Ministério Público Federal, na ordem de US\$682,6 milhões. Mas a lentidão da CVM não pode deixar de ser destacada. Ainda que acordos oferecidos por ex-executivos da empresa com o fim

8 O processo no momento se encontra em grau de recurso. 
de encerrar as investigações sancionatórias tenham sido negados, não há até o momento notícias de punições efetivas aos investigados.

\section{CONCLUSÃO}

A governança corporativa tem como objetivo a obtenção de um melhor alinhamento entre os interesses da companhia e dos stakeholders. Fica claro que nos desafios impostos à Petrobrás, diante do escândalo que atingiu a companhia com a operação Lava Jato, a governança corporativa apresentou falhas, que geraram inclusive a suspensão da companhia dos quadros associativos do IBGP geraram consequências ainda mais nefastas aos investidores minoritários.

A alta concentração na estrutura de propriedade das companhias brasileiras, com a presença marcante de um acionista controlador tem impactos na estrutura da governança corporativa se comparada a países como os Estados Unidos, em que dificilmente se verá um acionista com mais de $20 \%$ das ações da companhia. De forma que os embates no Brasil se darão entre os controladores e os acionistas minoritários e os credores de longo prazo. Nesse sentido a garantia de alguma voz aos acionistas minoritários se revela de maior importância nas companhias brasileiras.

No Brasil a Lei 7913/1989 prevê a legitimidade do Ministério Público para propor, de ofício ou a requerimento da CVM, ação civil pública com o objetivo de proteger de maneira coletiva os investidores contra condutas ilícitas, mas é preciso destacar que, mesmo não sendo possível ignorar os riscos inerentes ao mercado de capitais, até o ano de 2004 apenas 10 acórdãos poderiam ser contabilizados com menção expressa ao diploma em questão, sem que nenhum desses acórdãos tivesse origem em alguma ação civil pública promovida pelo Ministério Público.

No entanto é curioso notar que a Lei 7913/1989, anterior a um maior desenvolvimento do mercado de capitais no Brasil, teve como inspiração a legislação americana, notadamente o que prevê na seção 20 (b) do Securities Act a legitimação da SEC para tomada de medidas judiciais com o fim de impedir a prática de determinados atos lesivos aos investidores, bem como, com o de reparar os prejuízos 
causados aos investidores, obrigando aos que praticaram o ato ilícito a depositarem os lucros assim obtidos, mas foi tímida com relação aos papéis previstos para a CVM.

A consolidação de boas práticas de governança nos Estados Unidos ganha destaque com a Lei Sarbanes-Oxley, que além de possuir medidas tendentes à fiscalização das atividades de auditoria e de repressão a fraudes, visa maior transparência nas demonstrações financeiras. A Petrobrás por negociar papéis na bolsa de Nova lorque é obrigada a observar os ditames contidos na legislação em comento. De modo que os escândalos de corrupção, com a abrupta redução do seu valor de mercado, e a produção de demonstrações financeiras com aumento de ativo, e ainda, a garantia aos investidores de que a companhia tinha aderido a uma série de princípios éticos e que mantinha um controle severo nas contas a fim de prevenir a fraude e a corrupção, fundamentaram a propositura de diversas class actions que culminaram nos acordos firmados entre a companhia e os investidores, e ainda a SEC. Resultado diverso na ação proposta no Brasil, que acabou por ser extinta sem julgamento de mérito, e sem que de fato uma punição mais severa tenha sido imposta a companhia.

O que se conclui é que a previsão contida na Lei 7913/1989 é insuficiente para assegurar o real ressarcimento aos acionistas minoritários, e ainda, que a governança corporativa tem de fato papel crucial na contribuição para a proteção desses acionistas em mercados onde se vislumbra uma maior concentração da propriedade.

\section{REFERÊNCIAS}

ALVIM, Arruda. Ação Civil Pública - Sua evolução normativa significou crescimento em prol da proteção às situações coletivas. In: MILARÉ, Édis. (Coord.). A ação civil pública após 20 anos: efetividade e desafios. São Paulo: Revista dos Tribunais, 2005.

ANDRADE, Adriana; ROSSETTI, José Paschoal. Governança Corporativa. Fundamentos, Desenvolvimento e Tendências. São Paulo: Atlas, 2004.

CHEN, Kevin C.W; CHEN, Zhihong; WEI, K.C. John. Legal protection of investors, corporate governance, and the cost of equity capital. 
COMPARATO, Fábio Konder; SALOMÃO FILHO, Calixto. Poder de Controle na Sociedade Anônima. 5 ed. Rio de Janeiro: Forense, 2008.

DIDIER JR., Fredie; ZANETI JR., Hermes. Curso de direito processual civil: processo coletivo. 10 ed. Salvador: JusPodivm, 2016.

DURNEV, A.; KIM, E.H. To steal or not to steal: firm attributes, legal environment, and valuation, Journal of Finance 60, 2005.

EIZIRIK, Nelson Laks. O conceito de valor mobiliário e o alcance da Lei $n^{\circ} 7913 / 89$. In: Aspectos Modernos do Direito Societário. Rio de Janeiro: Renovar, 1992.

G1. Petrobras fecha acordo de $\mathbf{R} \mathbf{3} \mathbf{3 , 6}$ bilhões para encerrar investigações nos EUA. $2018 . \quad$ Disponível em: https://g1.globo.com/economia/noticia/2018/09/27/petrobras-fecha-acordo-paraencerrar-investigacoes-nos-eua.ghtml. Acesso em: 27.set.2018

GOYOS JÚNIOR, D. N. Dicionário jurídico. São Paulo: Observador Legal, 2003.

GROSSMAN, S.; HART, O. The costs and benefits of ownership: A theory of vertical and lateral integration. Journal of Political Economy, 94, 1986.

JOHNSON, S.; SHLEIFER, A. Privatization and corporate governance. 120 Annual East Asian Seminar on Economics, 2001.

KOSLOWISKI, Wilson. Breves notas de Governança Corporativa acerca do Conflito de Interesses na Sociedade Anônima. In: CANTIDIANO, L. L., CORRÊA, R. (orgs.). Governança corporativa: empresas transparentes na sociedade de capitais. São Paulo: Lazuli Editora, 2004 (Série Apimec Disponível em: $<$ marceloazevedo.pro.br/.../textosociedadeanonimaegovernancacorporativa44494.do c>. Acesso em: 29 set. 2018.

LA PORTA, R., LOPEZ-DE-SILANES, F., SHLEIFER, A., VISHNY, R. Investor protection and corporate governance. Journal of Financial Economics 58, 2000.

LEAL, Ricardo Pereira Câmara, SILVA, André Luiz Carvalhal da, VALADARES, Silvia Mourthé. Estrutura de Controle das Companhias Brasileiras de Capital Aberto, In: RAC, v. 6, n. 1, Jan./Abr. 2002.

OLIVEIRA JÚNIOR, Fernando Antônio de Alencar Alves de. A tutela jurisdicional coletiva do investidos no mercado de capitais brasileiro. O papel do Ministério Público. In: FRAZÃO, Ana (Org.) Constituição, Empresa e Mercado. Brasília: Faculdade de Direito - UnB, 2017. 
PETROBRÁS. Fatos e Dados. Assinamos acordo para encerrar class action nos EUA. 2018. Disponível em: http://www.petrobras.com.br/fatos-e-dados/assinamosacordo-para-encerrar-class-action-nos-eua.htm. Acesso em 15 set. 2018.

PISTOR, Katharina. A Legal Theory of Finance. In: Journal of Comparative Economics, v. 41, n. 2, 2013, Columbia Public Law Research Paper n. 13-348. Disponível em: <http://blogs.law.columbia.edu/glawfin/files/2013/10/02-A-LegalTheory-of-Finance-by-Katharina-Pistor.pdf>. Acesso em: 29 set. 2018.

PRATS, J. Y.; LASAGNA, M. Gobernabilidad y democracia.

RIBEIRO, Milton de Nassau. Aspectos jurídicos da governança corporativa. São Paulo: Quartier Latin, 2007.

SILVEIRA, Alexandre Di Miceli da. Governança corporativa no Brasil e no mundo teoria e prática. Rio de Janeiro: Elsevier, 2015.

Corporate Governance Quality and Firm Value in Brazil, School of Economics, Management and Accounting of University of São Paulo (FEA/USP).

. Governança Corporativa e Estrutura da Propriedade: Determinantes e Relação com o Desempenho das Empresas no Brasil.

SROUR, Gabriel. Práticas Diferenciadas de Governança Corporativa: Um Estudo sobre a Conduta e a Performance das Firmas Brasileiras. 